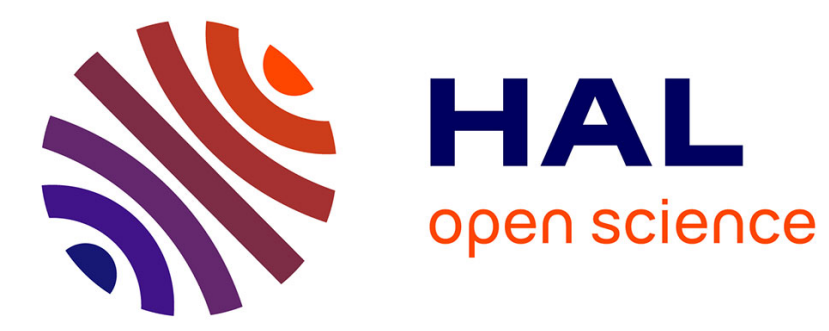

\title{
Methods for studying earthworm dispersal
}

\author{
Jérôme Mathieu, Gaël Caro, Lise Dupont
}

\section{To cite this version:}

Jérôme Mathieu, Gaël Caro, Lise Dupont. Methods for studying earthworm dispersal. Applied Soil Ecology, 2018, 123, pp.339-344. 10.1016/j.apsoil.2017.09.006 . hal-02147520

\section{HAL Id: hal-02147520 \\ https://hal.sorbonne-universite.fr/hal-02147520}

Submitted on 4 Jun 2019

HAL is a multi-disciplinary open access archive for the deposit and dissemination of scientific research documents, whether they are published or not. The documents may come from teaching and research institutions in France or abroad, or from public or private research centers.
L'archive ouverte pluridisciplinaire HAL, est destinée au dépôt et à la diffusion de documents scientifiques de niveau recherche, publiés ou non, émanant des établissements d'enseignement et de recherche français ou étrangers, des laboratoires publics ou privés. 
1 Methods for studying earthworm dispersal

2 Jérôme Mathieu ${ }^{1}$, Gaël Caro ${ }^{2}$, Lise Dupont $^{3}$

$4 \quad{ }^{1}$ Sorbonne Universités, UPMC Univ Paris 06, UPEC, Paris 7, CNRS, INRA, IRD, Institut

5 d'Ecologie et des Sciences de l'Environnement de Paris, 75005, Paris, France

62 UMR 1121, Université de Lorraine - INRA, Laboratoire Agronomie et Environnement, 2

7 Avenue Forêt de la Haye, 54518 Vandoeuvre, France

$8{ }^{3}$ Université Paris Est Créteil (UPEC), UPMC Univ Paris 06, Paris 7, CNRS, INRA, IRD,

9 Institut d'écologie et des sciences de l'environnement de Paris, 94010 Créteil Cedex, France

Abstract

Dispersal is a key driver of species composition and functional traits in earthworm communities. However, it has been largely overlooked in ecological literature on earthworms because it is particularly difficult to study. In this publication, we review recent developments that have been made in this field of research. We present methods to assess dispersal distance, such as Capture-Mark-Recapture and molecular tools, and methods using dispersal corridors or X-ray imagery aiming at identifying the mechanisms triggering dispersal in earthworms communities.

Keywords

21 Movements, landscape structure, connectivity, behavior, capture mark recapture methods 


\section{Introduction}

Dispersal plays a major role in shaping biodiversity, evolution, and ecosystem functioning. It connects localities together through fluxes of individuals and alleles. The direct consequence is that species abundance and genetic composition in different places of a landscape are not independent. In other words, local population abundance, genetic structure and community structure not only depend on local factors and processes such as habitat features, demography, genetic drift or species sorting and competition, but are also dependent on the properties of neighboring populations and communities (Leibold et al., 2004). In this perspective, we need to study local community and genetic structure at both local and regional scales in order to understand the structure of local populations or communities, as well as their functional role.

The magnitude of the dependence between local and regional scales directly results from dispersal rate. Theoretically, when dispersal is very high, local sites are well interconnected and tend to behave like a unique population or community (Economo and Keitt, 2008; Mouquet and Loreau, 2003). Local interactions are then a major driver of species composition and a low genetic differentiation among populations is expected. When dispersal is very low, local sites are isolated and behave like islands. Local populations and communities are well differentiated and severe genetic drift occurs. Extinction risk is then high for small populations. In nature, dispersal is generally between these two extremes, and complex behaviors such as source - sink dynamics may occur. In such case, certain sites can act as sources of dispersers (source), while others behave like sinks. Such dynamics can prevent extinction or speciation in certain sites. Local populations connected by dispersal are called "metapopulation" (Hanski and Gilpin, 1997), local communities connected by dispersal are called "metacommunity"(Leibold et al., 2004). In both cases, we need to understand the 
drivers and the magnitude of dispersal in order to understand the behavior and the properties of the system, either at local and regional scales.

Dispersal is usually defined as the movement of individuals away from their natal habitat, or from their usual home range, to a new habitat (Clobert et al., 2012). It is usually decomposed in three successive steps. First step is departure from the usual home range. Second is the transfer between the departure site and the arrival site. Third is the establishment in a new habitat (Fig. 1).

Figure 1

All these steps can originate from two very distinct processes: it can come from individuals' own willing, a process called "active dispersal", or from movements driven by an external force such as wind, water runoff, displacement by another animal, or by human activities (Matthysen, 2012). Dispersal direction is generally controlled in active dispersal but not in passive dispersal.

Studying dispersal is challenging for all organisms (Nathan, 2001), because it is hard to track individuals. This is particularly true for earthworms, because they are subterranean and cannot be seen from surface. Several approaches have been developed to address these difficulties, and can be classified in two groups. The first ones focus on dispersal patterns. They intend to measure typical dispersal distances of organisms during life span, or during a precise period of time. This approach aims at producing a histogram of distances travelled over a period of time, the so called "dispersal kernel" (Nathan et al., 2012). It is thus centered on the spatiotemporal aspects of the dispersal. The second group of methods focuses on the factors that 
drive dispersal, such as habitat quality or conspecific density. The products of this approach are dispersal rules, like positive density dependent dispersal. This approach is often framed in game theory and evolutionary ecology. It aims at predicting dispersal behavior and understanding the reasons why different dispersal behaviors evolved.

In this work, we present techniques that are currently available to study earthworms' dispersal from these two angles: 1) dispersal distances and 2) the factors that drive dispersal.

\section{Methods for studying earthworm dispersal distance}

One of the most basic question regarding dispersal of organisms is to determine how far they can move. In order to address this point, we need to estimate the distribution of the distances travelled for a given period of time. For this, two kinds of movements are often defined : the usual and most frequent movements, related to foraging, and the rare long distances movements (Nathan et al., 2008). In this framework, true dispersal usually refers to the rare and long distances dispersal events (LDD), located in the tail of the dispersal distribution(Nathan et al., 2012). These rare events play a critical role in colonization processes and invasion processes (Trakhtenbrot et al., 2005).

The estimation of traveling distances is challenging for earthworms, but can be done in two broad ways: by tagging and by studying the genetic profiles of individuals or populations.

\subsection{Tags}

Methods based on tags usually share the same principle: a group of individuals is captured, marked with a tag, then released at a known location in the field or in an experimental device. After a period of time, the marked individuals are searched at proximity from the release point. The distribution of the recapture distances from the release point (Fig. 3A) gives the 
"dispersal kernel" of the individuals over the respective period of time. These methods are generally referred to as Capture Mark Recapture (CMR) methods (Seber, 1982). They are better suited for short distances estimation than for LDD. In theory, individuals can be released and recaptured several times, but this is difficult to achieve in the field on earthworms. Variations in CMR methods include the type of tags, the capacity to use tags specific to individuals, and the number of recapture events. In earthworms, several types of tags have been used so far. Early attempts used food colorants such as E102 + E132 (green) or E124 (red) and red biological stains such as Safranin and Phloxine (Mazeaud, 1979). More recently, ${ }^{15} \mathrm{NH} 4+$ and $\mathrm{U}-{ }^{13} \mathrm{C}$ glucose (Dyckmans et al., 2005), Rubidium (Ben Hamou et al., 2007), or ${ }^{60} \mathrm{Co}$ (Capowiez et al., 2001) have been used with success. However, all these methods are difficult to apply because they require a significant equipment or lab work to detect the tags, because they are not visible with naked eyes. We now present in detail two recent methods that circumvent these caveats.

\subsubsection{Visual Tags for earthworm: VIE}

Visible Implant Elastomers (VIE, Fig. 2A\&B and 3A) are colored tags that are injected below the skin (Butt and Lowe, 2007; Gonzalez et al., 2006). They are injected in a liquid state but soon become solid through a polymerization process. They are available from Northwest Marine Technology, Inc (http://www.nmt.us/) and are relatively affordable.

Figure 2

This kind of tags has been used with success on a variety of organisms such as fish, frogs, turtles and seeds, in order to assess population size or dispersal distance. They are visible 
through the skin of the animals, particularly with a UV light. The tags are well supported by earthworms (Butt et al., 2009). They can stay up to 27 months in their body, which is much longer than the previously mentioned tags (Butt et al., 2009).

Figure 3

The main drawback of this method is the impossibility of monitoring individuals in a continuous manner. It is not possible to track individuals between two capture events. Marking and recapturing require a lot of time, and tags are hardly specific to individuals, even though combining tags of different colors is possible for large individuals ( $>1.5 \mathrm{~g}$, Fig. 2B). This method requires releasing a high number of marked animals for statistical reasons, which can trigger density dependence dispersal (McCrea and Morgan, 2014). Indeed, in many species, high level of conspecific density leads to active dispersal (Caro et al., 2013; Mathieu et al., 2010). Finally, statistical methods for capture recapture data are complex (Amstrup et al., 2005; Lee and Chao, 1994). Despite these difficulties, this approach is very useful to get an estimation of the dispersal kernel of individuals.

\subsubsection{Electronic tags: RFID tags}

A new promising technique is the use of miniaturized RFID tags (Radio Frequency IDentification. These tags (Fig.4) offer the possibility to mark each individual specifically, with a unique barcode ID. A scanner (Fig. 4B) retrieves the ID of an individual when the tag is close enough from the receptor, typically less than $0.5 \mathrm{~cm}$. 
Detecting individuals in a continuous fashion can be achieved by installing antennas at the surface of the ground, which detect any individual with a tag that comes close to the antenna. This offers the possibility to track individuals continuously and at different sites.

This method suffers from several limitations that still impede its use on a regular base. First, RIFD tags are more harmful than VIE tags. They are bigger $(1.4 \mathrm{x} 8 \mathrm{~mm})$ and are frequently ejected out of the body by earthworms. During preliminary tests, only larger individuals, typically $>1 \mathrm{~g}$, supported them. Second, detection can only be done at very short distance from the antenna $(<0.5 \mathrm{~cm})$, and cannot be done through the soil. Even if the antenna can be buried, it is much more efficient to detect individuals on the surface. Thus, this technique is better suited for large epigeic and anecic species, which crawl on surface, but not for endogeic ones. Third, the tags are completely invisible once injected, which makes it difficult to find their location in the body during manual scanning, or to determine if an individual is tagged or not. A VIE can be injected in addition, close to the RIFD tag, however this increases the risk of mortality. At the moment, miniaturized RFID can only be detected by the scanners provided by the RFID manufacturers, which are expensive and have a limited efficiency. However, in the future it should be possible to build its own system of scanners or antenna and data logger.

\subsection{Molecular approach}

155 Recent progresses in molecular biology offer new opportunities for the estimation of dispersal distance of earthworms from genetic data (Dupont, 2009; Torres-Leguizamon et al., 2012; Zeller et al., 2012). As dispersal leads to gene flow, genetic information can be used to infer dispersal patterns. They can be assessed in two ways: first by comparing observed 
populations' genetic structure to theoretical ones under no dispersal, and second by statistical assignment methods that allow identifying the parents or the population of origin of individuals, based on their genetic profile (Broquet and Petit, 2009). In addition, the effect of landscape structure on dispersal patterns can be assessed with the tools developed within the framework of landscape genetics (Manel et al., 2003). The principle is to determine if there is any relationship between the spatial patterns of populations' genetic structure, or individuals' genetic profile, and landscape features. This approach was applied at the plot scale $(100 \times 50 \mathrm{~m})$ on the earthworm Allolobophora chlorotica (Dupont et al., 2015). It suggested that soil properties influence dispersal in the field, and estimated that gene flow occurs at approximately 7 m.year- 1 . At the landscape level, it showed the role of landscape features on the dispersal of two earthworm species, A. chlorotica and Aporrectodea icterica (Dupont et al., 2017).

Figure 5

The genetic approach is based on the variation of highly variable DNA sequences (i.e. molecular markers) which are selectively neutral (i.e. the variation is not selected by the environment). Microsatellites, Amplified fragment length polymorphisms (AFLPs), and single nucleotide polymorphisms (SNPs) are typical markers used for this kind of study (Dupont et al., 2011; Torres-Leguizamon et al., 2012). Because population genetic models are dedicated to diploid $(2 \mathrm{~N})$ species, this kind of approach can hardly be used for studying dispersal of earthworm species with a ploidy level different to $2 \mathrm{~N}$. Once the molecular data are acquired, they can be matched with landscape data in two ways. First, they can be compared to landscape structure in the neighborhood of the sampling sites (Fig. 5). For this, 
an area (a "buffer") is defined around each sampling site, and the relevant features of landscape structure are described with the help of a GIS. For instance, the distance to the nearest forest, the percentage of crops or the length of roads can be computed (McGarigal and Marks, 1995). The result of this process is a table describing different landscape features for each sampling site. These features can then be matched with genetic descriptors of populations, such as allelic richness and heterozygote frequency, using, for instance, traditional regression techniques. The second way to proceed is through connectivity analysis. In this case, the landscape is considered in its totality, not only around a certain radius of each sampling site. In this approach, all sites are compared by pairs, both in terms of genetic difference and geographical distance (Fig. 5). This is done by correlating the geographical distance between pairs of sites to their genetic distance. If there is any significant relationship between the two matrixes, it suggests that landscape feature, and thus dispersal, has an influence on spatial genetic structure. Geographical distance is calculated by estimating the cumulated costs of movements between each pairs of sites. For this, specific costs are attributed to the different elements of the landscape. The product of this step is a "resistance map". This map is used to calculate the cumulative traveling costs between each pair of sites, using different algorithms of movements. Finally, either the cost of the shortest path, or the weighted mean of the different paths, is used to estimate the distance between all pairs of sites (McRae et al., 2008). The final product of this step is a pairwise squared distance matrices giving the traveling costs between pairs of sites. This process can be realized with different scenario of costs. By comparing different scenarios of costs, this technique allows identifying which elements are most likely to play a role on dispersal, either by facilitating it (corridors) or by impeding it (barriers) (Dupont et al., 2017). In order to match the distance matrix with genetic features, the genetic differentiation between all sampling sites must also be estimated. This can be done through different indices, but the most widespread is the fixation index Fst 
(Wright, 1951). The result of this step is a pairwise squared dissimilarity matrix between sites.

In order to correlate the matrix of genetic differentiation to the matrixes of traveling costs, specific statistical techniques must be used, because the same sites are involved in several comparisons, and there is non independency in the residuals. The historical technique used for this was Mantel test, but it has been criticized and the recommend test is now MLPE (Maximum Likelihood Population Effect). This technique identifies the scenario of costs that match with differences in genetic structure (Van Strien et al., 2012)

\section{Methods for studying mechanisms of earthworm dispersal}

Another important aspect in the study of dispersal is to determine the conditions that drive individuals to disperse. These drivers can be internal, such as body size, hormonal status and age, or external, such as habitat quality or biotic interactions (Clobert et al., 2012). In earthworms, only external drivers of dispersal have been studied so far. Two techniques are now well established: the dispersal corridors (Mathieu et al., 2010), and the X ray imagery

223 (Caro et al., 2012).

\subsection{Dispersal corridors}

The principle of dispersal corridors is to expose individuals to a stimuli, to wait a certain amount of time, and then to compare the movements of individuals in the stimuli treatment to the control (Clobert et al., 2012). In this kind of experiment, it is necessary to be able to make the difference between active dispersal and random diffusion. Active dispersal results from a decision to leave a patch, without knowing in advance where to go, and what type of environment will be available after leaving the initial patch. Random diffusion results from 
usual movements, such as foraging, that do not imply a decision to leave. To be able to make the distinction between active dispersal and random diffusion, a specific experimental setup must be used (Fig. 6).

Figure 6

The experimental device is elongated and separated in three parts: 1) the "departure section"; 2) the "crossing section"; 3) the "settlement section". The "departure section" is the section where the stimuli or the control treatment is implemented, and where the earthworms are inoculated. The treatment can consist for example in soil quality, litter quality, conspecific density, or interspecific density. The crossing section must be an unhospitable soil, which individuals would cross only if the conditions in the departure section are really unhospitable. This is the key point to make the distinction between random diffusion and active dispersal. The "settlement section" must contain a very hospitable soil, which individuals will not leave once they reached it. In top of that, it is required to put litter on the surface of the departure and of the settlement zones, even for endogeic species. After a fixed period of time after inoculation, the soil and the litter of the tree sections are separated and the number of earthworms in each section is retrieved. The percentage of dispersal is compared between control and stimuli treatment with a logistic model (Caro et al., 2013).

\section{$1.3 \mathrm{X}$ ray imagery}

Another promising tool is $\mathrm{X}$ ray imagery. This method takes advantage of recent progress in imagery machines. It consists in using $\mathrm{X}$ ray imaging device such as Philips Diagnostic $\mathrm{C}$ 
generator to scan the soil (Fig. 7). This kind of device is capable of differentiating earthworms and their gallery in the soil, if the soil is less than $6 \mathrm{~cm}$ thick. The soil must not be too mineral otherwise $\mathrm{X}$ ray cannot penetrate. Adding soft material, such as peat, greatly increase image quality. Introducing by incision a small metal tag $(1 \mathrm{~mm})$ below the skin of individuals can also help to localize them on the $\mathrm{X}$ ray shots. With this kind of setup, it is possible to determine in real time the location of individuals in the ground (Caro et al., 2012), to tell if it is located inside or outside a gallery, and to measure its movement speed [VIDEO].

Figure 7

\section{Conclusion}

265 The several techniques that now exist to study earthworm dispersal (Table 1) can give us 266 insights about dispersal distances and mechanisms leading to active dispersal, either in the

267 field or in experimental devices. They offer new opportunities to quantify this process, and to 268 estimate its contribution to population dynamics, community assembly, and finally ecosystem 269 functioning.

\section{Acknowledgments}

272 We would like to thank Augusto Zanella for his commitment in this Special Issue of Applied 273 Soil Ecology

\section{$274 \quad$ References}


Amstrup, S.C., McDonald, T.L., Manly, B.F.J., 2005. Handbook of Capture-Recapture Analysis. Princeton University Press, Princeton.

Ben Hamou, M., Kulhánek, A., Lacombe, S., Whalen, J.K., 2007. Marking earthworms for release-recapture studies using the trace element rubidium. Appl. Soil Eco. 36, 41-45.

Broquet, T., Petit, E.J., 2009. Molecular estimation of dispersal for ecology and population genetics. Annual Review of Ecology, Evolution and Systematic 40, 193-216.

Butt, K.R., Briones, M.J.I., Lowe, C.N., 2009. Is tagging with visual implant elastomer a reliable technique for marking earthworms? Pesquisa Agropecuária Brasileira 44, 969-974. Butt, K.R., Lowe, C.N., 2007. A viable technique for tagging earthworms using visible implant elastomer. Appl. Soil Eco. 35, 454-457.

Capowiez, Y., Renault, P., Belzunces, L., 2001. Three-dimensional trajectories of 60Colabelled earthworms in artificial cores of soil. Eur. J. Soil Sci. 52, 365-375.

Caro, G., Abourachid, A., Decaëns, T., Buono, L., Mathieu, J., 2012. Is earthworms' dispersal facilitated by the ecosystem engineering activities of conspecifics? Biol. Fert. Soils 48, 961965.

Caro, G., Decaëns, T., Lecarpentier, C., Mathieu, J., 2013. Are dispersal behaviours of earthworms related to their functional group? Soil Biol. Biochem. 58, 181-187.

Clobert, J., Baguette, M., Benton, T.G., Bullock, J.M., 2012. Dispersal Ecology and Evolution. Oxford University Press, Oxford, p. 796.

Dupont, L., 2009. Perspectives on the application of molecular genetics to earthworm ecology. Pedobiologia 52, 191-205.

Dupont, L., Grésille, Y., Richard, B., Decaëns, T., Mathieu, J., 2015. Dispersal constraints and fine-scale spatial genetic structure in two earthworm species. Biol. J. Linn. Soc. 114, 335347. 
Dupont, L., Lazrek, F., Porco, D., King, R.A., Rougerie, R., Symondson, W.O.C., Livet, A., 300 Richard, B., Decaëns, T., Butt, K.R., Mathieu, J., 2011. New insight into the genetic structure

of the Allolobophora chlorotica aggregate in Europe using microsatellite and mitochondrial data. Pedobiologia 54, 217-224.

Dupont, L., Torres-Leguizamon, M., Rene-Corail, P., Mathieu, J., 2017. Landscape features impact connectivity between soil populations: a comparative study of gene flow in earthworms. Mol Ecol 26, 3128-3140.

Dyckmans, J., Scrimgeour, C.M., Schmidt, O., 2005. A simple and rapid method for labelling earthworms with ${ }^{15} \mathrm{~N}$ and ${ }^{13} \mathrm{C}$. Soil Biol. Biochem. 37, 898-993.

Economo, E.P., Keitt, T.H., 2008. Species diversity in neutral metacommunities: a network approach. Ecol Lett. 11, 52-62.

Gonzalez, G., Espinoza, E., Liu, Z., Zou, X., 2006. A Fluorescent Marking and Re-count Technique Using the Invasive Earthworm, Pontoscolex corethrurus (Annelida: Oligochaeta).

Caribbean Journal of Science 42, 371-379.

Hanski, I., Gilpin, M., 1997. Metapopulation Biology: Ecology, Genetics, and Evolution. Academic Press, London, UK.

Lee, S.-M., Chao, A., 1994. Estimating Population Size via Sample Coverage for Closed Capture - Recapture Models. Biometrics 50, 88-97.

Leibold, M.A., Holyoak, M., Mouquet, N., Amarasekare, P., Chase, J.M., Hoopes, M.F., Holt, R.D., Shurin, J.B., Law, R., Tilman, D., Loreau, M., Gonzalez, A., 2004. The metacommunity concept: a framework for multi-scale community ecology. Ecol Lett. 7, 601-613.

Manel, S., Schwartz, M.K., Luikart, G., Taberlet, P., 2003. Landscape genetics: combining landscape ecology and population genetics. Trends in Ecology \& Evolution 18, 189-197. Mathieu, J., Barot, S., Blouin, M., Caro, G., Decaëns, T., Dubs, F., Dupont, L., Jouquet, P., Nai, P., 2010. Habitat quality, conspecific density, and habitat pre-use affect the dispersal 
behaviour of two earthworm species, Aporrectodea icterica and Dendrobaena veneta, in a mesocosm experiment. Soil Biol. Biochem. 42, 203-209.

Matthysen, E., 2012. Multicausality of dispersal: a review, Dispersal Ecology and Evolution. Oxford University Press, Oxford, pp. 1-18.

Mazeaud, D., 1979. Evaluation de methodes de marquage permettant le repérage des lombriciens; premières application. Paris 06, Institut National Agronomique Paris Dijon, p. 178.

McCrea, R.S., Morgan, B.J.T., 2014. Analysis of Capture-Recapture Data. Chapman and Hall/CRC Press.

McGarigal, K., Marks, B.J., 1995. FRAGSTATS: spatial pattern analysis program for quantigying landscape structure, Gen. Tech. Rep., PNW-GTR-351, Portland, Oregon, USA. McRae, B.H., Dickson, B.G., Keitt, T.H., Shah, V.B., 2008. Using circuit theory to model connectivity in ecology and conservation. Ecology 89, 2712-2724.

Mouquet, N., Loreau, M., 2003. Community Patterns in Source-Sink Metacommunities. Am. Nat. 1321, 544-557.

Nathan, R., 2001. The challenges of studying dispersal. Trends in Ecology \& Evolution 16, 491-493.

Nathan, R., Getz, W.M., Revilla, E., Holyoak, M., Kadmon, R., Saltz, D., Smouse, P.E., 2008. A movement ecology paradigm for unifying organismal movement research. Proceedings of the National Academy of Sciences 105, 19052-19059.

Nathan, R., Klein, E., Robledo-Arnuncio, J.J., Revilla, E., 2012. Dispersal kernels: review, in: Clobert, J., Baguette, M., Benton, T.G., Bullock, J.M. (Eds.), Dispersal Ecology and Evolution. Oxford University Press, Oxford, pp. 187-210.

Seber, G., 1982. The Estimation of Animal Abundance and Related Parameters. Macmillan, New York. 
349 Torres-Leguizamon, M., Mathieu, J., Livet, A., Decaëns, T., Dupont, L., 2012. Isolation of

350 polymorphic microsatellite markers in Aporrectodea icterica (Savigny 1826) Soil Biol.

351 Biochem. 51, 16-19.

352 Trakhtenbrot, A., Nathan, R., Perry, G., Richardson, D.M., 2005. The importance of long-

353 distance dispersal in biodiversity conservation. Diversity and Distributions 11, 173-181.

354 Van Strien, M.J., Keller, D., Holderegger, R., 2012. A new analytical approach to landscape

355 genetic modelling: least-cost transect analysis and linear mixed models. Molecular Ecology

$35621,4010-4023$.

357 Wright, S., 1951. The genetical structure of populations. Annals of Eugenics 15.

358 Zeller, K., McGarigal, K., Whiteley, A., 2012. Estimating landscape resistance to movement:

359 a review. Landscape Ecology 27, 777-797. 
363 Fig. 1 - Dispersal is usually decomposed in three steps: Emigration from the source, transfer, 364 and immigration to a new site.

365 Fig. 2 - A/ Tagging of a small Allolobophora chlorotica B/ An individual of Aporrectodea 366 longa tagged with two yellow bands.

367 Fig. 3 - Summary of the steps required to study earthworm dispersal with tags.

368 Fig. 4 - A/ Picture of a RFID tag ready to be injected. B/ The scanner recognizes a tagged 369 Allolobophora chlorotica individual.

370 Fig. 5 - Overview of the workflow to perform landscape genetics on earthworm.

371 Fig. 6 - Example of a dispersal corridors with its three sections. The triangle indicates the 372 inoculation point of earthworms.

373 Fig. 7 - Experimental setup to take X ray shots of earthworms in the soil. 
Table 1 Comparison of the methods currently available for studying earthworm dispersal.

377

\begin{tabular}{|c|c|c|c|c|c|c|c|c|c|c|}
\hline Method & $\begin{array}{l}\text { Focus on } \\
\text { dispersal }\end{array}$ & Type of method & $\begin{array}{l}\text { Estimation } \\
\text { of dispersal }\end{array}$ & $\begin{array}{l}\text { Type of } \\
\text { dispersal }\end{array}$ & Spatial extent $\dagger$ & Place & Cost & $\begin{array}{l}\text { Computing } \\
\text { complexity } \\
\ddagger\end{array}$ & $\begin{array}{l}\text { Time } \\
\text { required } \ddagger\end{array}$ & $\begin{array}{l}\text { References } \\
\S\end{array}$ \\
\hline Landscape genetics & Distance & Molecular & indirect & passive & ++ to +++ & Field & $\$ \$ \$ \$$ & +++ & +++ & 1) \\
\hline VIE Tags & Distance & $\begin{array}{l}\text { Capture Mark } \\
\text { Recapture }\end{array}$ & direct & active & + to ++ & $\begin{array}{l}\text { Field \& } \\
\text { Lab }\end{array}$ & $\$ \$$ & ++ & ++ & 2) \\
\hline RFID Tags & Distance & $\begin{array}{l}\text { Capture Mark } \\
\text { Recapture }\end{array}$ & direct & active & + to ++ & $\begin{array}{l}\text { Field \& } \\
\text { Lab }\end{array}$ & $\$ \$ \$$ & ++ & ++ & 3) \\
\hline Dispersal corridors & Mechanisms & Experimental & direct & active & + & $\mathrm{Lab}$ & $\$$ & + & + & 4) \\
\hline $\mathrm{X}$ rays & Mechanisms & Experimental & direct & active & + & $\mathrm{Lab}$ & $\$ \$$ & + & + & 5) \\
\hline
\end{tabular}

$379+:+=$ small extent, $+++=$ large extent, $\ddagger:+=$ least, $+++=$ most, $\S$ References : 1) Dupont, L. and al ., 2017. Mol Ecol 26, 3128-3140. 2) Butt, K.R., Lowe, C.N., 380 2007. Appl. Soil Eco. 35, 454-457, 3) unpublished, 4) Mathieu J. and al., 2010. Soil Biol. Biochem. 42, 203-209. 5) Caro and al. , 2012. Biol. Fert. Soils 48, 961- 
DISPERSAL

$1^{\circ}$

$3^{\circ}$

Emigration $\quad 2^{\circ}$ Transfer 

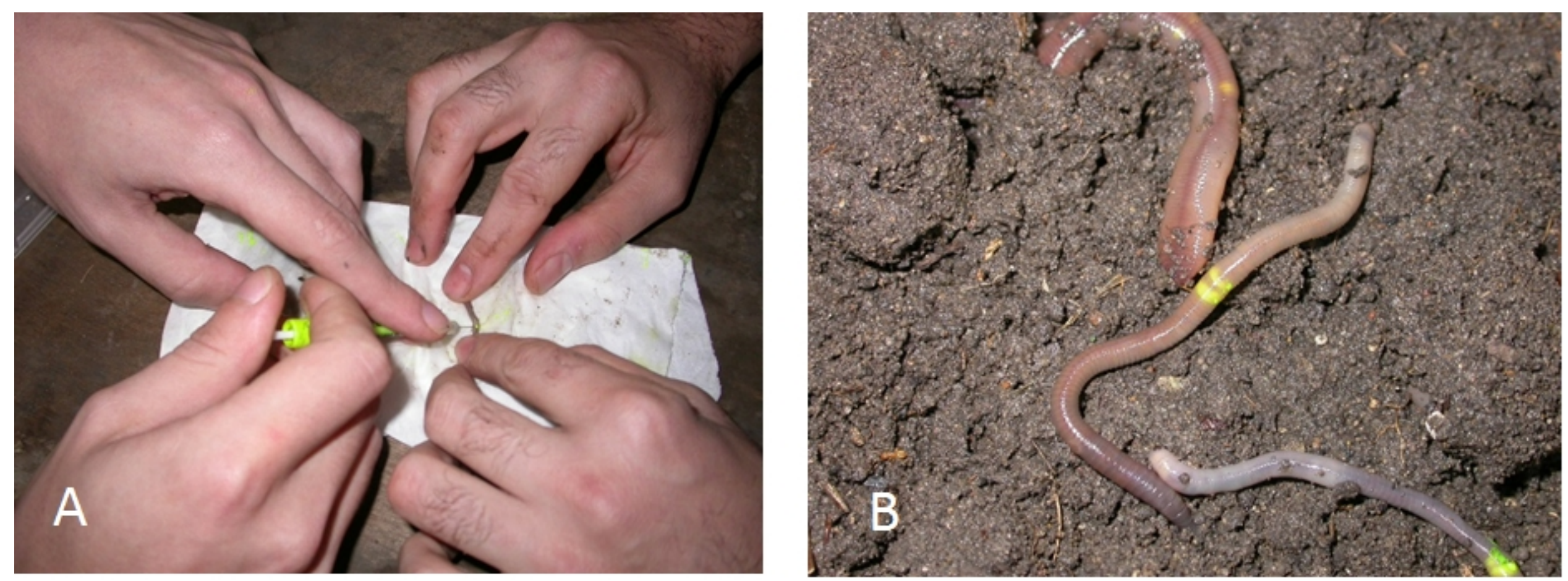
A/ VIE Tags
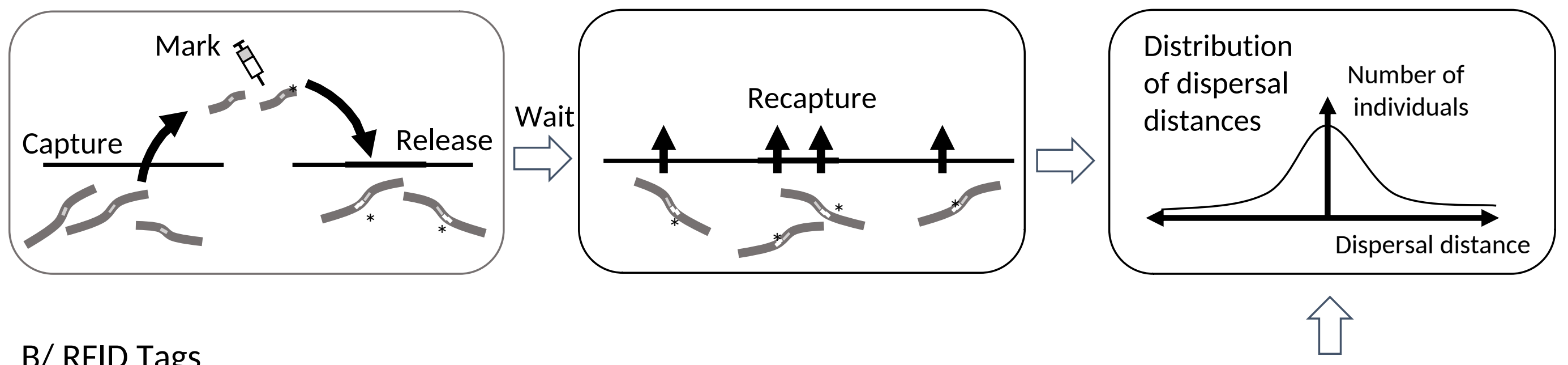

B/ RFID Tags
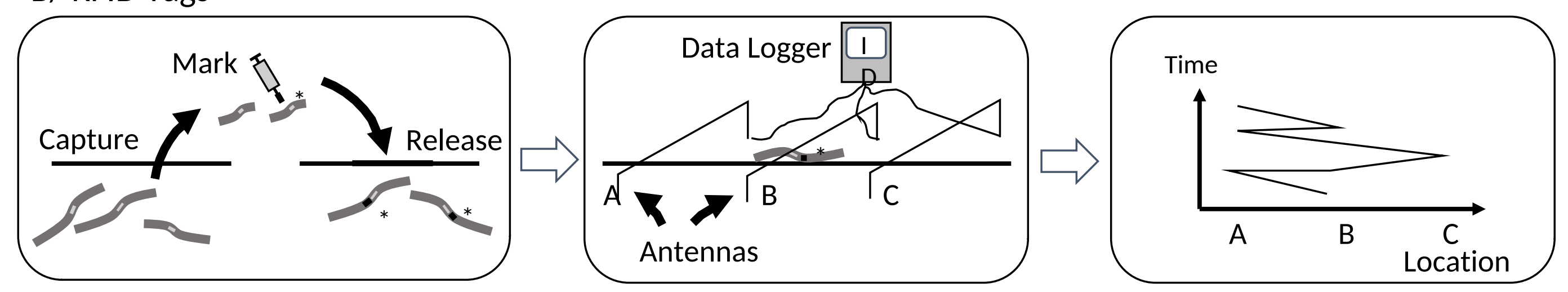

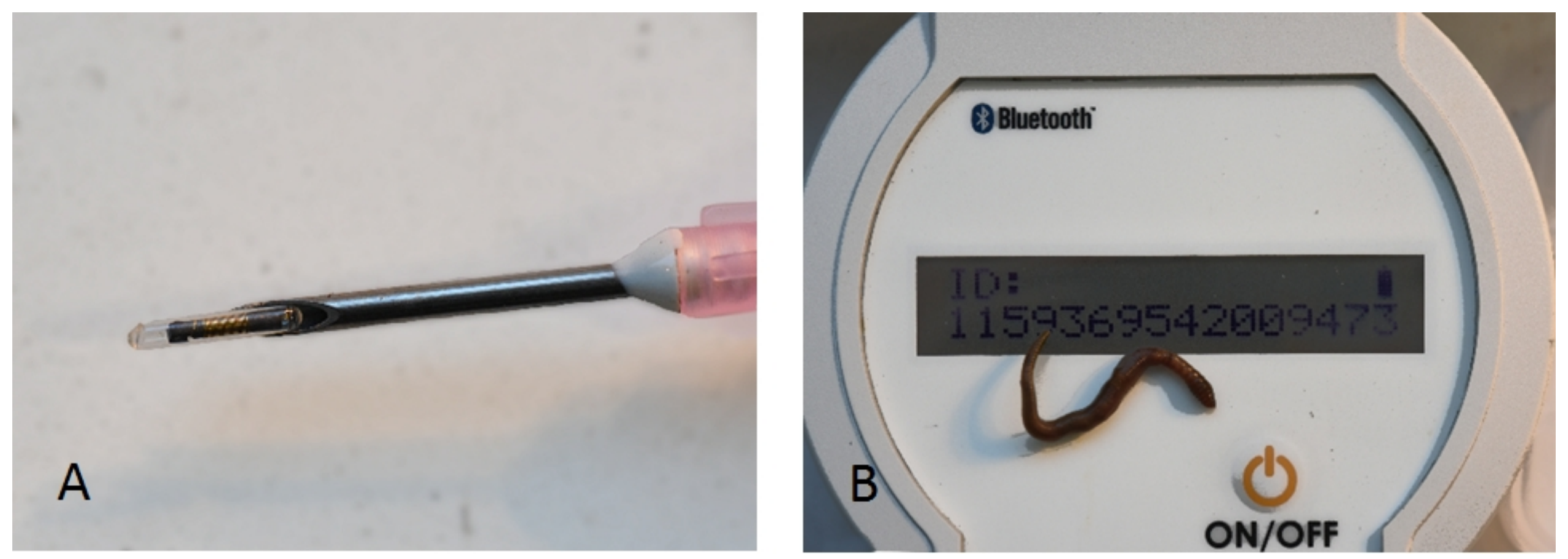


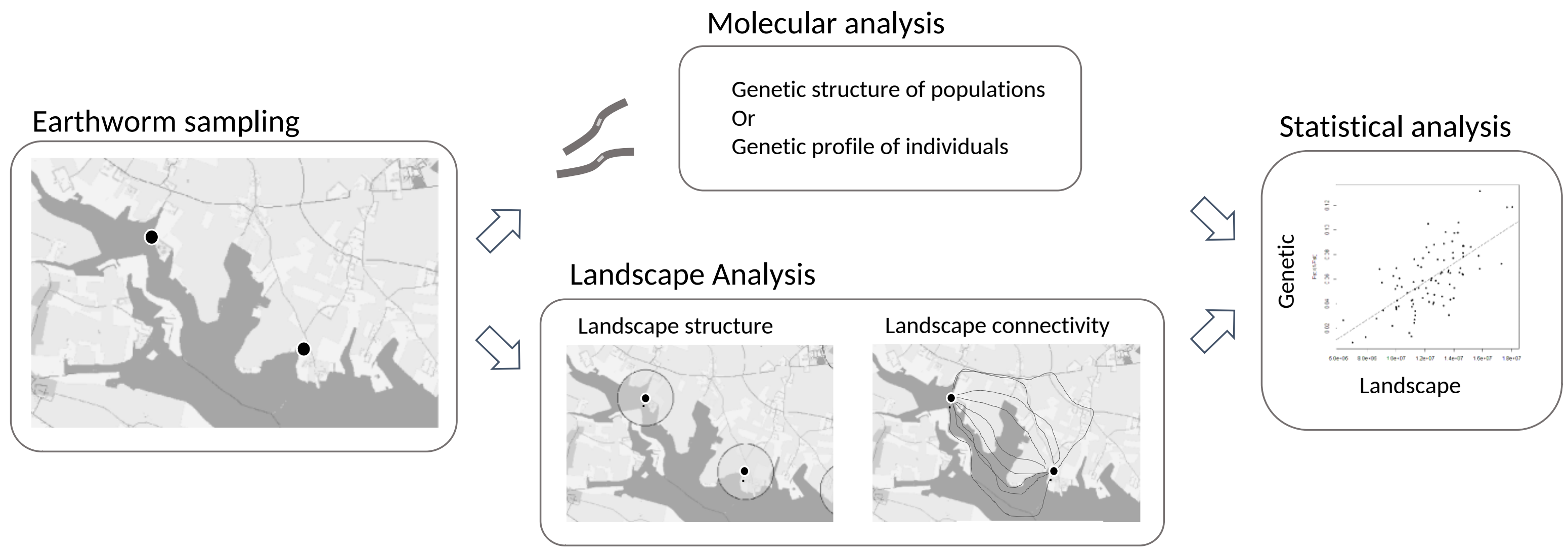




\section{Inoculation}

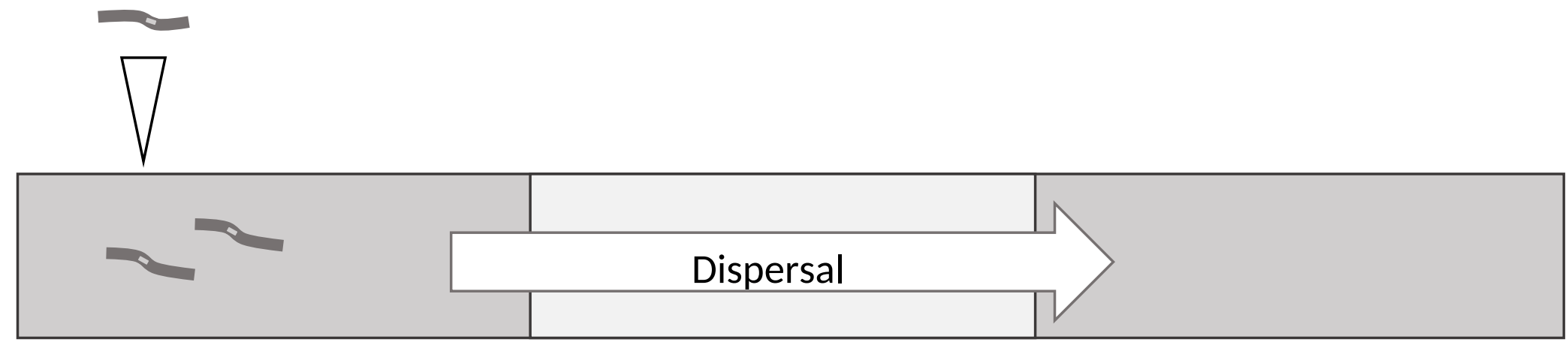

Departure section

Crossing section

Settlement section 


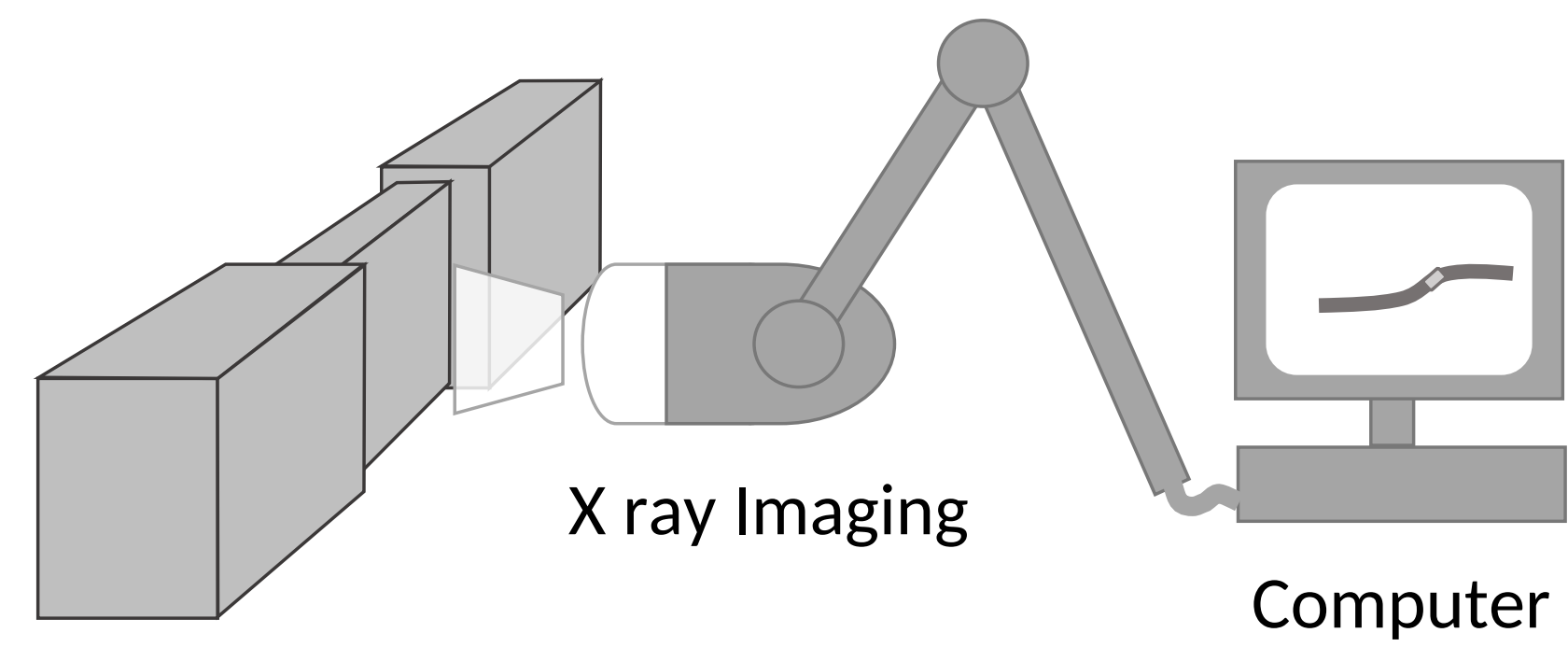

Experimental device 